\title{
Research and Analysis on Production Safety Management of Power Enterprises \\ Shang Chao ${ }^{1}$ and Liao Wei $^{2}$
}

\author{
1. Power Research Institute of State Grid Jiangxi Electric Power Company \\ 2. state grid nanchang electric power supply company
}

Keywords: Power Enterprise; Safety Management; Improvement Plan

\begin{abstract}
With the continuous improvement of China's economy, power enterprises are becoming more and more important in the process of economic construction. Safe production of power enterprises is the key to improving the level of power supply. Safety management is an important task in the development of power enterprises. It is also an effective way to improve the development level of power enterprises and improve the quality of power enterprises. During the production and operation process, power enterprises must actively strengthen the emphasis on safety production, solve problems existing in the traditional safety management process, and improve power supply stability. At the same time, in the power enterprise safety management process, a sound emergency management system should be established. When a power safety accident occurs, the fault problem can be solved in time according to the emergency plan to ensure the safety of power transmission. This paper analyzes and discusses the problems and countermeasures in the management of power enterprises, aiming to continuously innovate the concept of safe production of power enterprises.
\end{abstract}

\section{Introduction}

With the continuous improvement of people's material living standards, the demand for electricity in the home is also increasing, and the technology is constantly accelerating. A series of new technologies such as ultra-high voltage, ultra-high voltage direct current transmission, and electric power information are gradually entering the power industry. But because these are new technologies, they face the challenge of security. At the same time, since the birth of the power company, the company itself has been constantly exploring a reasonable management model, initially by a static, centralized, government-managed. They are unable to respond to the needs of effective government authority subordinates to develop and evolve into national power that enables complex systems and timely responses to highly dynamic, diverse and ever-changing needs. Institutions within the industry, ideology and corporate culture are also changing, and this series of changes has made electrical safety a higher demand. This paper starts with an overview of power grid enterprise security management, analyzes the development of power enterprises and the problems existing in security management, analyzes the causes from specific problems, and finally proposes measures for power enterprises security management. Through the research in this paper, it is hoped to improve and strengthen the work of security basic management. In order to strengthen the source management of safe production, we can insist that the focus of safety production work moves down, and the gate moves forward. When the accident is still in its infancy, it will be solved, so that the grid enterprises can operate safely and steadily.

\section{Analysis of the Importance of Safe Production of Power Enterprises}

The safe production of power enterprises is related to the stability of various industries and the whole society.

In short, power enterprises are the main basic industries for revitalizing China's national economy. It is a publicly-owned industry in the society. It provides electricity services to many industries such as agriculture, national defense, and transportation in China. It is the basic demand 
of people in daily life. Especially after the occurrence of a power grid accident, it will directly cause a large-scale power outage, which will have an impact on the production of various industries, directly forming a production pause and awkwardness. It will even bring a series of disasters, causing economic losses and casualties, and the losses are incalculable. On the other hand, once there is a problem with the power supply, it will also affect the order of people's lives.

The safe production of power enterprises is directly related to the power industry

The ability of enterprises to produce safely is a prerequisite for smooth development. When a company has a security incident, there is no way to achieve civilized production. When the enterprise's system fails, the relevant departments such as power plants and substations that are formed in the system will not be able to operate normally, and eventually the power production and transmission and distribution will be in a very chaotic state. Therefore, the power enterprise itself needs to be able to produce safely.

Due to the characteristics of electricity production itself, safe productionis also required.

As we all know, electric power supply companies are a huge overall system. The electric energy produced by the power plant is sent to the user via the booster substation, transmission line, step-down substation, and distribution line. The whole process involves production, supply, and sales, but the entire electrical energy cannot be stored on a large scale. Therefore, production, supply, and sales are basically carried out at the same time.

The labor environment at electric power production requires safe production.

That is to say, the power enterprise production environment itself has the following characteristics. First of all, there are many electrical and related equipment, high temperature and high-pressure equipment, power plant boilers, steam turbines, heat pipes, etc. Then there are many flammable and explosive toxic objects, such as coal, fuel, strong acid, hydrogen cooling equipment, followed by high-speed rotating machinery, such as generators, fans, motors, etc. ;There are many special operations, such as live working, aerial work, lifting and welding operations. These characteristics show that the working conditions and environment of electric power production are very dangerous and complicated, and the greater insecurities are formed in them, and they are highly risky. These potential threats directly constitute harm to the lives of employees. Once there is a leak or negligence in the work, these potential literature factors will be aroused and directly cause danger. Therefore, the labor environment for electric power production requires safe production.

\section{Problems with the Safe Production Management of Power Enterprises}

Safe management system is not perfect.

Due to the heavy power production tasks and the high market competition pressure of power enterprises, in the development of power enterprises, they often pay attention to the economic benefits of power production, but instead pay less attention to safety issues. The lack of safety awareness in the production process of enterprises leads to the lack of a safety management system. Even if the relevant safety management system is formulated, it is only a form, resulting in a large safety hazard in the power production process.

Corporate employees have a weak awareness of safe production.

Human resources are the important competitiveness of power enterprises, and high-quality talents can promote the sustainable development of power enterprises. However, due to the low comprehensive ability of many employees and the lack of awareness of safety production, employees are not actively operating in accordance with the rules and regulations in the production process, and illegal operation requirements, which in turn poses a safety hazard.

There is a lack of emergency response mechanism.

In the process of power production and power transmission, various emergencies often occur, such as excessive voltage causing equipment to be burned, short circuit, cable damage, etc. , which will affect the timely transmission of electrical energy products. Electric power emergency management is a key link in the process of power production and power transmission. However, the current emergency management mechanism of power enterprises is not perfect. There is no unified planning and management department in power enterprises. The departments are relatively loose 
and do not form strong cohesive force, which makes the emergency handling work difficult.

Production equipment needs to be further updated

The safety production of power enterprises is inseparable from the mechanical equipment, ensuring that all kinds of equipment are in good working condition can improve the production level of power enterprises. At present, the production equipment of some power enterprises in China is relatively backward and has not been updated in time. In addition, the maintenance and maintenance of equipment in the production process is not in place, which makes the safety accidents more and more.

\section{Countermeasures to Strengthen the Security Management of Power Enterprises}

Strengthen education on safety management

The purpose of production is to accomplish the goal, and in order to achieve the goal, safety management can bring optimized effects to specific cases in the environment of certain related objects, which is a strong guarantee in the production process. As a safety management education for production and life, there are many different things.

Improve the safety management system and implement the responsibility system for safety management

Establishing a well-established supervision and supervision mechanism for the safety production of power enterprises is of great significance for the improvement of the safety management level of power enterprises. In view of the loopholes in the existing supervision and supervision mechanisms of power enterprises in China, relevant government departments should strengthen the supervision and supervision mechanism of power enterprises from various aspects such as legal construction, administrative supervision, public opinion supervision, and internal supervision of enterprises. Efforts should be made to place the operation of power enterprises under strict and effective supervision and supervision mechanisms.

Conduct normal and regular safety production assessments within power enterprises.

For high-risk operations such as power enterprises, it is very important to establish a normalized and regular enterprise safety production and safety management assessment. The so-called normalized safety production assessment, that is, the assessment of the equipment, personnel, management and other aspects of the daily operation of power enterprises, in order to find potential and possible unsafe hidden dangers, and timely to various types of accidents that may lead to unsafe accidents. Factors are cleaned up to ensure that the company's normal production activities are carried out safely. Therefore, it is necessary for power enterprises to establish a normalized daily safety production evaluation mechanism, and to implement assessment consciousness and behavior into every department and every employee of the enterprise. It is necessary to clarify responsibilities and establish an evaluation team led by leaders at all levels to evaluate the safety production rules and regulations. At the same time, in this process, it is necessary to have not only clear responsibilities and mechanisms, but also to implement the assessment work in practice and avoid the phenomenon of "staying on the surface and taking the form".

\section{Conclusion}

Power production is an important part of China's economic production process. Various fault problems often occur in the power production process. Power safety production accidents are an important reason for the development of power enterprises. In order to promote the sustainable development of power enterprises, we must actively strengthen the importance of power enterprises safety management, improve the safety accident emergency response system and mechanism, improve the safety management awareness of employees, and promote the safe production of power enterprises. 


\section{References}

[1]Stere R, Duma M, Styrbu M. Telemetering Systems Developed at the Electrical Research Institute of the Ministry of Heavy Industry (Rumanian People's Republic)[J]. Seizure, 2015, 21(9):665-678.

[2]Zhong-Dong M A, Han Y, Liang S G, et al. Research on Upgrading of Electrical Appliances Industry Cluster for Qingdao District - an Empirical Study Based on DMI Model[J]. Journal of Liaocheng University, 2015.

[3]Yang H B, Yang S G, Zhang L P, et al. Application Status and Research Progress of Silicone Rubber in Electrical Industry[J]. Silicone Material, 2016.

[4]Lyon S W, Quesada-Pineda H J, Crawford S D. Reducing Electrical Consumption in the Forest Products Industry Using Lean Thinking[J]. Bioresources, 2014, 9(1):1373-1386.

[5]Sun Z C, Shen J X, Jin M J, et al. Research of the influence of different PWM inverters on the iron losses for induction motors[C]// International Conference on Electrical Machines and Systems. IEEE, 2015:96-100.

[6]Zhang X L, Polytechnic E. Under the Background of Cross-border Electricity Business English Talent Demand and Teaching Model Research[J]. Journal of Hubei Correspondence University, 2017.

[7]Hasanah H, Muh N M. Competency Mapping Based Work Area Electrical Industry Classification for Vocational Education and Training[C]// Upi International Conference on Technical and Vocational Education and Training. 2015.

[8]Zeng X Y, Yang H L, Shi-Yao L I, et al. The Design of Household Appliance Telephone Remote Control System with Self-learning Function[J]. Research \& Exploration in Laboratory, 2016.

[9]Monteiro F R, Pereira P A, Cordeiro L C, et al. Complementary training programme for electrical and computer engineering students through an industrial-academic collaboration[C]// Frontiers in Education Conference. IEEE, 2016:1-9.

[10]Pellegrini M, Rassaei F. Modeling daily electrical demand in presence of PHEVs in smart grids with supervised learning[C]// IEEE, International Forum on Research and Technologies for Society and Industry Leveraging A Better Tomorrow. IEEE, 2016:1-6.

[11]Isoc D. Preventing plagiarism in engineering education and research[C]// International Symposium on Fundamentals of Electrical Engineering. IEEE, 2015:1-7.

[12]Bruzzese C, Zito D, Tessarolo A. Finite reluctance approach: A systematic method for the construction of magnetic network-based dynamic models of electrical machines[C]// Aeit Conference - From Research To Industry: the Need for A More Effective Technology Transfer. IEEE, 2015:1-6.

[13]Wang Y F. Analysis of Financing Difficulties in Chinese PV Industry[J]. Advanced Materials Research, 2014, 960-961:1542-1545.

[14]Bhatt N J. Organisation Structure, Education Profile of Human Capital, Output and Productivity of Electrical Manufacturing Industry of India: A study of Selected Enteprises[C]// International Conference of Nepalese Academy of Management. 2013.

[15]Cook W D, Du J, Zhu J. Units invariant DEA when weight restrictions are present: ecological performance of US electricity industry[J]. Annals of Operations Research, 2017, 255(1-2):323-346. 